\section{Effects of Temperature and Pressure on Reservoir Fluids and Seismic Properties of Reservoir Rocks}

Received: 10-05-2020; Revised: 17-07-2020; Accepted: 25-07-2020.

\title{
ABSTRACT
}

The research work is an integrated attempt to enhance knowledge that how seismic properties are effected with pressure at constant temperature and with temperature at constant pressure. This research work is done using the data of UCH well 22 located near Sui in Middle Indus Basin and BOBI well 08 located in Sindh Province (Pakistan) in Lower Indus Basin. Graphically result shows that a compressional velocity, densities, effective densities, Bulk modulus and Bulk modulus of rock saturated has directly relationship with pressure at constant temperature for oil, gas and water. Graphically results also shows that a compressional velocities, densities, effective densities, Bulk modulus and Bulk modulus of rock saturated has inverse relationship with temperature at constant pressure for oil, gas and water.

Keywords: Seismic properties, Temperature, Pressure, Bulk Modulus, Rocks.

\section{INTRODUCTION}

$\mathrm{CH}$ gas field is located in the S-W part of the middle Indus Basin, in District Dera Bugti, Baluchistan. The Pakistan Petroleum Limited (PPL), the $2^{\text {nd }}$ largest Exploration \& Production Company in Pakistan discovered gas reserves at UCH gas field in 1955. The UCH gas field is elevated $100 \mathrm{M}$ (328 Feet) from the main sea level. The drilled well No: 01 was left abandoned due to the higher concentration of Carbon Dioxide $\left(\mathrm{CO}_{2}\right)$. In 1986, UCH Gas field was appraised by $\mathrm{OGDCL}$, which started Drilling activities in this area. After that, OGDCL developed the all required infrastructures for Gas Gathering for instance, Gas Dehydration Plant, $\mathrm{H}_{2} \mathrm{~S}$ Removal plant, Utilities and Gas Transmission Pipeline for the supply of gas to UPL's Power Generation Plant. UCH Gas Field is supplying treated gas to UPL Plant for their three gas turbines of $130 \mathrm{MW}$ each.

The Sui main structure is positioned in the Suleiman subbasin of the Indus basin. It is part of the first sets of folds emerging from the Indus flat plains west of the Indus River. The Siwaliks formation sediments from Miocene to Pleistocene age are exposed in this area. These late tertiary deposits composed of sandstone; clays and conglomerates have become folded and faulted in an accurate belt along the eastern flank of the Sibi re-entrant during various episodes of Himalayan Orogeny ${ }^{1}$.

The Laki formation of Lower Eocene age underlying Kirthar formation includes the Sui Upper Limestone (SUL), Ghazij shale and the Sui Main Limestone (SML). Sui upper limestone includes Limestone with inter-bedded shale whereas the Sui main limestone is predominantly Limestone with marl and thin shale marker beds in the basal part. The Paleocene age Ranikot formation predominantly composed of shale with some beds of Limestone and quartzose sandstones.

In Sui area, complete Cretaceous sequence from Pab formation to Sembar formation is present, which is composed of alternating clastic and carbonate intervals of Pab, Moghalkot, Parh, Goru and Sembar formations. Pab sandstone is a proven gas reservoir in Sui deep-1 well whereas; Moghalkot, Goru and Parh have also displayed rational gas shows during drilling of Sui Deep-1. Although, regional seismic correlation suggests lap out of Sembar formation before reaching Sui area and biostratigraphy of Sui deep-1 well confirms the presence of Sembar formation in this area.

During the time of middle Jurassic age the breakup of Gondwana land established carbonate platform sedimentation in this area, which has resulted in development of thick carbonates in the central part of the basin in the form of Chiltan formation. Sui Deep well had penetrated $120 \mathrm{~m}$ through the Chiltan formation.

Anticlinal structure is no longer a simple elongated anticline at Samber level as in the ease at the shallower mapped horizons but with the broader, it has slightly westward shifted crest and complex peripheries, especially the eastern plunge where faulting has contributed suggestively to the complexity of the structure. 
Upper Cretaceous Pab Formation is exposed in the SiahKoh anticline, and the Sken, Khup, Shamkatikani, and Giandari structures expose the Paleocene Dunghan Formation which is underlying by Shaheed Ghat Formation.

$\mathrm{BOBI}$ gas field is situated about 25 kilometers in south of District Sanghar and $85 \mathrm{~km} \mathrm{~N}$-E of Hyderabad city in Sindh province. In May 1988, first exploratory well BOBI-01 drilled and completed as gas / condensate producer and total 8 wells were drilled till year 1991. Extended production testing was made on $\mathrm{BOBI}$ wells so as to obtain reservoir parameters and estimation of reserves. BOBI Gas condensate field is a part of Second Oil \& Gas Development Project financed by Asian Development Bank (ADB) worth of 52.00 million \$ US out of which 20.1 million \$ US was owed for the development of BOBI field. Field was declared as Oil Complex in 2002 after the installation of Condensate fractionating facilities and gas-recycling system.

In Lower Indus Basin sedimentary rock deposit has a thickness up to $10,000 \mathrm{~m}$, including Mesozoic and Cenozoic sections. Precambrian basement is exposed in the southeastern part at Nagar Parkar high. Triassic to Recent age Lithostratigraphic units is present in lower Indus basin. However, recently the older sedimentary rock units from Precambrian to Cambrian and Permian age have been encountered in an oil and gas exploratory well named Marvi-1 drilled by Union Texas Petroleum (UTP), which is presently known as British Petroleum. Precambrian (salt range formation) and the Cambrian (Khewra, Kussak, Jutana, Baghanwala formations) sequencesare widely distributed in the upper Indus basin and diminish in the Salt and Surghar ranges.

Mesozoic rock sequence of the lower Indus basin represents several thousand meter thick Jurassic sequence i.e. Shirinab formation and Chiltan Limestone. Both are shallow water marine rocks consisting of limestone and shale with subordinate sandstone interbeded in the lower part ${ }^{2}$. The intra-Jurassic unconformity at the close of the Callovian time occurs throughout the Indus basin. The Jurassic/Cretaceous boundary is transitional in most parts of the Indus basin. There is a relative quiescence during late Jurassic to early cretaceous when similar lithofacies of the Sembar and Goru formations were deposited. Same situation continued in the middle cretaceous time when the deep water Parh Limestone, with radiolarian chert, was deposited throughout the region. Parh Limestone deposition indicates fragmentation of the basin with the development or upgrading of various structural highs. Cretaceous sequences above the Parh Limestone deposition not only have different lithologies but also have drastically variable thickness. The Mughal Kot formation of the early Maestrichtian comprises dark gray, calcareous mudstone and calcareous shales with intercalation of quartzose sandstone and light grey limestone. Another sequence of the Maestrichtian age is the Pab formation which consists mainly of quartzose sandstone and is widely developed throughout the lower Indus basin ${ }^{3}$.

The cretaceous / tertiary boundary is a major unconformity in this area. The rocks of Paleocene age are characterized by Ranikot Group. Ranikot Group consists of three formations, i.e. Khadro formation, Bara formation and Lakhra formation. The massive coal deposits of Sindh province, i.e Lakhra, Sonda and Thar are present in Bara formation ${ }^{4}$.

\section{MATERIALS AND METHODS}

\section{Effects of fluid saturation on seismic properties}

The seismic response of reservoir is directly controlled by (a) compressional velocities $V_{P}(b)$ shear velocity $V_{S}$ when the water content increases $\mathrm{P}$-wave velocity increase slightly whereas S-wave velocities decreases. In short Pwave and S-wave velocities are not helpful for indications of fluid saturation effect because of shear modulus and bulk density.

$$
\begin{aligned}
& \mathrm{V}_{\mathrm{p}}=\sqrt{\frac{\mathrm{K}+4 / 3 \times \mu}{\rho}}=\sqrt{\frac{M}{\rho}} \\
& \mathrm{V}_{\mathrm{s}}=\sqrt{\frac{\mu}{\rho}}
\end{aligned}
$$

Where $\mathrm{K}$ is bulk modulus, $\mu$ is shear modulus, $M$ is the compressional modulus, and $\rho$ is the bulk density.

$$
\rho_{\mathrm{eff}}=\phi \rho_{\mathrm{fl}}+(1-\phi) \rho_{\mathrm{min}}
$$

$\rho_{\text {eff }}=$ Effective density, $\varphi=$ Porosity, $\rho_{\mathrm{fl}}=$ Density of fluid, $\rho_{\text {min }}=$ Density of mineral

\section{Gassmann's equation}

Gassman's equations provide a way to calculate the bulk modulus of a fluid-saturated porous medium using the known bulk moduli of the solid matrix, of the frame, and of the pore fluid. For a rock, the solid matrix consists of the rock-forming minerals, the frame refers to the rock sample with empty pores (dry rock), and the pore fluid can be a gas, oil, water, or a mixture ${ }^{5}$. The Gassmann's formulation is

$K_{s}=K_{d}+\Delta K_{d}$

$$
\Delta K_{d}=\frac{K_{0}\left(1-K_{d} / K_{0}\right)^{2}}{1-\varphi-K_{d} / K_{0}+\varphi \times K_{0} / K_{f}}
$$

$\mathrm{U}_{\mathrm{s}}=\mu_{\mathrm{d}}$

Where $K_{0}=$ bulk moduli of mineral grain, $K_{f}=$ bulk moduli of fluid frame, $K_{d}=$ bulk moduli of dry rock frame, $K_{s}=$ bulk moduli of saturated rock frame, $\phi=$ bulk moduli of porosity, $\mu_{s}=$ share modulus of saturation rock, $\mu_{d}=$ share modulus of dry rock 


\section{Effects of fluids on seismic velocities}

Seismic explorations are done to identify the pore fluids their depth and the mapping of hydrocarbon deposits. In sedimentary rock the fluids can widely vary in composition and physical properties. Seismic interpretation is usually based on these fluids properties and their effects which they impart to the rocks ${ }^{4}$.

We will discuss the properties of two primary type pore fluids (a) hydrocarbon gases (b) hydrocarbon liquids (oils). At elevated pressure the properties of oils and gases merge with each other and the difference between gas and oil phases become valueless.

Different Gassmann models have been developed which describes the effect of pore fluids on rock density and seismic velocity. For example Gassmann,s 19515; Biot, $1956^{2}$. In these models the fluid density and bulk modulus are the fluid parameters which are used. And due to fluid viscosity effect there is dispersion in velocity.

\section{Seismic properties and gas saturated rocks}

Gas phase is easiest to characterize. Hydrocarbons gases are usually consist of light alkanes (methane, ethane, propane, etc) additional gases are also present depending on the pressure, temperature, and history of the deposit. SUCH as water vapor and heavier hydrocarbon. The gas mixtures are characterized by a specific gravity, $\mathrm{G}$, the ratio of gas density to air density at $15.6^{\circ} \mathrm{C}$, and atmospheric pressure. It is a good sign for us when only a rough idea of the gas gravity is known we able to get a good estimation of gas properties at a specific temperature and pressure.

For an ideal gas velocity increases with temperature and there is no change in velocity due to pressure.

$$
\overline{\mathrm{V}}=\frac{R T a}{P}
$$

Where $\mathrm{P}$ is pressure, $\mathrm{V}$ is the molar volume, $\mathrm{R}$ is the gas constant, and $\mathrm{T} a$, is the absolute temperature $\mathrm{T}_{\mathrm{a}}=\mathrm{T}\left({ }^{\circ} \mathrm{C}\right)$ +273.151 . This equation leads to a density $\rho$ of

$\rho=\frac{M}{\bar{V}}=\frac{M P}{R T_{a}}$

Where $\mathrm{M}$ is the Compressional Modulus. The isothermal compressibility $\beta_{\mathrm{T}}$ is

$$
\beta \mathrm{T}=\frac{1}{\overline{\mathrm{V}}}\left(\frac{a \bar{V}}{a P}\right)_{T}
$$

Where the subscript $\mathrm{T}$ indicates isothermal conditions. If we calculate the isothermal compressional wave velocity $\mathrm{V}_{\mathrm{T}}$ we find

$$
\mathrm{V}_{\mathrm{T}}^{2}=\frac{1}{\beta \mathrm{TP}}=\frac{\mathrm{RT}_{\mathrm{a}}}{\mathrm{M}}
$$

Hence, for an ideal gas velocity increases with temperature and is independent of pressure.

In most solid materials, the difference between the isothermal and adiabatic compressibilities is negligible. Adiabatic compressibility is related to isothermal compressibility through $\gamma$, the ratio of heat capacity at constant pressure to heat capacity at constant volume; i.e.,

$\gamma \beta_{\mathrm{s}}=\beta \gamma$

The heat capacity ratio can be written in terms of the more commonly measured constant pressure heat capacity thermal expansion, isothermal compressibility, and volume ${ }^{6}$.

$$
\frac{1}{\gamma}=\frac{\mathrm{Ta} \overline{\mathrm{V}} \alpha^{2}}{\mathrm{C}_{\mathrm{P}} \beta_{\mathrm{T}}}
$$

These properties can be derived from an equation of state of the fluid and a reference curve of $\mathrm{Cp}$ at some given pressure.

Compressibility factor $\mathrm{Z}$ is;

$$
\overline{\mathrm{V}}=\frac{Z R T_{a}}{P}
$$

Adiabatic bulk modulus Ks is,

$$
\frac{1}{\beta_{s}}=\frac{\gamma P}{\left(1-\frac{P}{Z} \frac{\partial Z}{\partial P}\right)}
$$

The modulus can be obtained, therefore, if $Z$ can be adequately described.

$\mathrm{P}_{\mathrm{pr}}$ and pseudoreduced pressure

$\mathrm{P}_{\mathrm{pr}}=\mathrm{P} / \mathrm{P}_{\mathrm{pc}}=\mathrm{P} /(4.892-0.4048 \mathrm{G})$

$\mathrm{P}_{\mathrm{pr}}$ and pseudoreduced temperature

$\mathrm{T}_{\mathrm{pr}}=\mathrm{T}_{\mathrm{a}} / \mathrm{T}_{\mathrm{pc}}=\mathrm{T}_{\mathrm{a}} /(94.72+170.75 \mathrm{G})$

Gas densities derived from the Thomas et al., (1970) ${ }^{7}$. Alternatively, for the pressures and temperatures typically encountered in oil exploration, we can use the approximation? ${ }^{7}$.

$\rho \cong \frac{28.8 G P}{Z R T_{a}}$

Where

$Z=\left[0.03+0.00527\left(3.5-T_{p r}\right)^{3}\right] P_{p r}+\left(0.642 T_{p r}-0.007 T^{4} p r-\right.$

$$
0.52)+E(2.18)
$$

And

$E=0.109\left(3.85-T_{p r}\right)^{2} \exp (-[0.45+8(0.56-$ $\left.\left.\left.1 / \mathrm{T}_{\mathrm{pr}}\right)^{2}\right] \mathrm{P}^{1.2} \mathrm{pr} / \mathrm{Tpr}\right)$

The adiabatic gas modulus $\mathrm{K}_{\mathrm{s}}$ is also strongly dependent on composition. 


$$
\cong \frac{P}{\left(1-\frac{P p r}{Z} \frac{\partial Z}{\partial P_{p r}}\right)_{T}}
$$

Where

$$
\gamma_{0}=0.85+\frac{5.6}{\left(P_{p r}+2\right)}+\frac{27.1}{\left(P_{p r}+3.5\right)^{2}}
$$

\section{Seismic properties and oil saturated rocks}

Crude oil can be mixtures of very complex organic compounds. Natural oils are made up of the range of light liquids with low carbon number to very heavy tars. At very extreme we get Bitumen and Kerogen which may be denser tan water and acts as a solid and at light extreme due to the change in temperature $\&$ pressure the process of condensity occur by this we get liquids. Under pressure light oils can be absorb large quantities of hydrocarbon gases. In result of this the moduli and density decrease change in composition and ability to absorb gases produced wide variations in the seismic properties of oil. As we calculate the moduli and densities for gases we can also calculate the moduli and density of oil by using general equation of state for oils. These equations are present in petroleum engineering literature ${ }^{8}$.

API $=\frac{141.5}{\rho_{0}}-131.5$

This API number is often the only description of oil that is available. The variable compositions and ability to absorb gases produce wide variations in the seismic properties of oils. However, these variations are systematic and by using p. or the API gravity we can make reasonable estimates of oil properties. Where $\rho_{0}$ is specific density.

If we had a general equation of state for oils, we could calculate the moduli and densities as we did for the gases ${ }^{9}$.

Generally, away from phase boundaries, the velocities, densities, and moduli are quite linear with pressure and temperature. In organic fluids typical of crude oils, the moduli decrease with increasing temperature or decreasing pressure.

For oil that remains constant in composition, the effects of pressure and temperature are largely independent. The pressure dependence is comparatively small and the published data for density at pressure $\mathrm{pp}$ can be described by the polynomial.

$\rho_{\mathrm{p}}=\rho_{\mathrm{o}}+\left(0.00277 \mathrm{P}-1.7 \mathrm{t} \times 10^{-7} \mathrm{P}^{3}\right)\left(\mathrm{P}_{\mathrm{o}}-1.15\right)^{2}+3.49 \times 10^{-}$

${ }^{4} \mathrm{P}+3.49 \times 10^{-4} \mathrm{P}$

The effect of temperature is larger, and one of the most common expressions used to calculate the in-situ density was developed by Dodson and Standing (1945) ${ }^{4}$.

$P=P_{p} /\left[0.972+3.81 \times 10^{-4}(T+17.78)^{1.175}\right]$
Wang et al., (1988) ${ }^{10}$ showed that the ultrasonic velocity of a variety of oils decreases rapidly with density (increasing API). A simplified form of the velocity relationship they developed is

$$
\begin{gathered}
\mathrm{V}=2096\left(\frac{P_{0}}{2.6-p_{o}}\right)-3.7 \mathrm{~T}+4.64 \mathrm{P}+0.0115[4.12 \\
\left.\left(1.08 \mathrm{P}_{0}^{-1}-1\right)^{1 / 2}-1\right) \mathrm{TP}
\end{gathered}
$$

In form of API

$$
\left(0.36 \mathrm{API}^{1 / 2}-1\right) \mathrm{TP} \quad(2.26)
$$$$
V=15450(77.1+A P I)^{-1 / 2}-3.7 T+4.64 P+0.0115
$$

Where $\mathrm{V}$ is velocity in $\mathrm{m} / \mathrm{s}$. using this relationship with the density, we get the oil modulus.

\section{Seismic Properties and Water Saturated Rock}

The concentration of salts in water makes water saturated in salts and called as brine. Most common pore fluid is brine. Composition of brine can range from pure water to saturated saline solution. Local salinity is often disturbed by ground water flow, shale dewatering, or adjacent salt beds and domes. Increase in temperature causes velocity inversion in water and brines. Density of brine increases with the increase in salinity. Specific volume and compressibility of various salt solutions at pressure over a limited temperature range ${ }^{11}$.

Data on sodium chloride solutions were provided by Potter and Brown (1977) ${ }^{12}$. Using these data a simple polynomial in temperature, pressure and salinity can be constructed to calculate the density of sodium chloride solution ${ }^{9}$.

$\mathrm{p}_{\mathrm{w}}=1+1 \times 10^{-6}\left(-80 \mathrm{~T}-3.3 \mathrm{~T}^{2}+0.00175 \mathrm{~T}^{3}+489 \mathrm{P}-2 \mathrm{TP}+\right.$ $\left.0.016 T^{2} P-1.3 \times 10^{-5} T^{3} P-0.333 P^{2}-0.002 T P^{2}\right)$

And

$\mathrm{p}_{\mathrm{B}}=\mathrm{pw}+\mathrm{S}\left(0.668+0.44 \mathrm{~S}+1 \times 10^{-6}[300 \mathrm{P}-2400 \mathrm{PS}+\mathrm{T}\right.$ $(80+3 T-3300 S-13 P+47 P S)]\}$

Where $p_{w}$ is density of water in $g / \mathrm{cm}^{3}$ and $p_{B}$ is density of brine in $\mathrm{g} / \mathrm{cm}^{3}$ and $\mathrm{S}$ is weight friction $(\mathrm{ppm} / 1000000)$ of sodium chloride.

Wilson provides a relationship for the velocity $V_{w}$ of pure water to $100^{\circ} \mathrm{C}$ and about $100 \mathrm{MPa}^{13}$.

$\mathrm{V}_{\mathrm{W}}=\sum_{i=0}^{4} \sum_{j=0}^{3} w_{i j} T^{i} P^{j}$

A simplified form of velocity function with constants can be modified to fit the additional data ${ }^{3}$.

$V_{B}=V_{W}+S\left(1170-9.6 T+0.055 T_{2}-8.5 \times 10-5 T^{3}+2.6 P-\right.$ $\left.0.0029 T P-0.0476 P^{2}\right)+$ S1.5 $\left(780^{-10} P+0.16 P^{2}\right)-820 S 2$ (2.30) 


\section{Seismic properties and rock saturated by fluid mixture}

From an exploration standpoint, mixtures of pore fluids of liquid and gas phases are extremely important. A gas reservoir or oil reservoir about the water contact usually has substantial water trapped in the pore spaces. Gas often resolves from oil due to the drop of pressure during production. The seismic character of $\mathrm{UCH}$ oil reservoirs can change significantly with time. Hence, for geophysical examinations of reservoirs we must have a way to drive the properties of mixed pore fluid mixtures. The density of a mixture is given as

$$
\rho \text { m }=\varphi_{\mathrm{A}} \rho_{\mathrm{A}}+\varphi_{\mathrm{B}} \rho_{\mathrm{B}}
$$

Here $\rho \mathrm{m}$ is the mixture density $\rho_{\mathrm{A}}$ and $\rho_{\mathrm{B}}$ are the densities of components, $\varphi_{\mathrm{A}}$ and $\varphi_{\mathrm{B}}$ are the volume fractions of components $A$ and $B^{14,15}$.

Assuming the pressure in the two phases equal, the effective modulus of mixed fluid can be calculated using equation.

$$
\mathrm{d} \overline{\mathrm{V}}_{\mathrm{A}}=\left(-\bar{V}_{A} B_{A} \partial P\right) S=\left(\frac{\bar{V}_{A}}{K_{A}} \partial P\right)_{S}
$$

Where $K_{A}$ is the adiabatic bulk modulus and $B_{A}$ is the compressibility of component $A$. The total volume change for the mixture will be the sum of these changes.

For a mixture, Wood's equation

$$
\begin{gathered}
\frac{1}{K M}=\frac{1}{\bar{V}_{A}+\bar{V}_{B}} \frac{1}{\partial P}\left(\frac{\bar{V}_{A}}{K_{A}} \partial P+\frac{\bar{V}_{B}}{K_{B}} \partial P\right) \\
=\frac{\phi_{A}}{K_{A}}+\frac{\phi_{B}}{K_{B}}
\end{gathered}
$$

\section{RESULTS AND DISCUSSION}

Seismic technologies have gained a central position in the reservoir delineation and monitoring with improved resolution and cost efficiency. Rock physics plays a vital role in connecting the seismic data to the presence of insitu hydrocarbons and the reservoir characteristics. The effect of fluid on the rock velocity and density is a basic procedure that is adopted to know the effect of pore fluid on seismic data. Seismic velocity changes resulting from different fluid saturation in reservoir or calculated by Gassmann's equations. These equations are widely used in analysis of different hydrocarbons indicators (DHI), for example amplitude "Bright spots" amplitude variations with offset (AVO) and time-lapse reservoir monitoring.

The pore space modulus in response to changes in fluid modulus is very vital. He introduced an effective fluid coefficient by differentiating the bulk modulus of the fluid filled pore space K-pore. Two ratios were determined (a) the ratio of fluid modulus to slid grain modulus. (b) The ratios of Biot's coefficient to priority. Sometimes problems arose in automated analysis in which results are usually taken at face value.

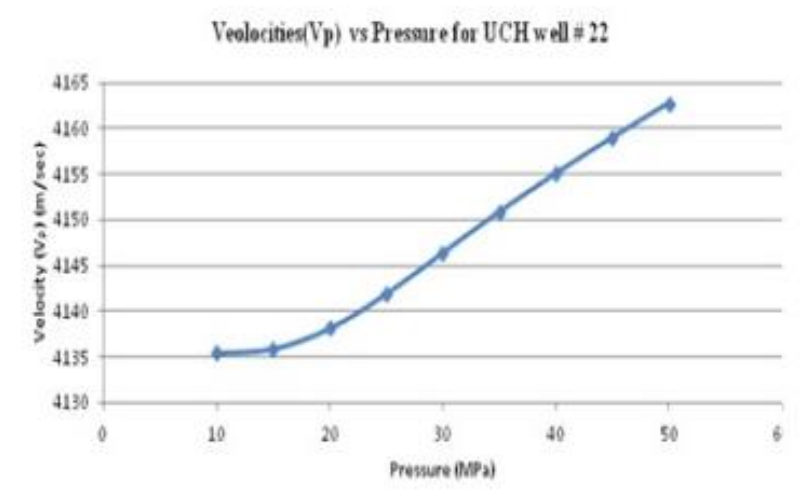

Figure 1: Graph between velocity $\mathrm{V}_{\mathrm{P}}$ and pressure of $\mathrm{UCH}$ well NO: 22.

This graph 1 shows the relationship between Velocity and Presseure, Which are directly propotional to each other. Hence, as the velocity inceases Presure also increases. Whereas, tepmerature has kept constant during performing the analysis.

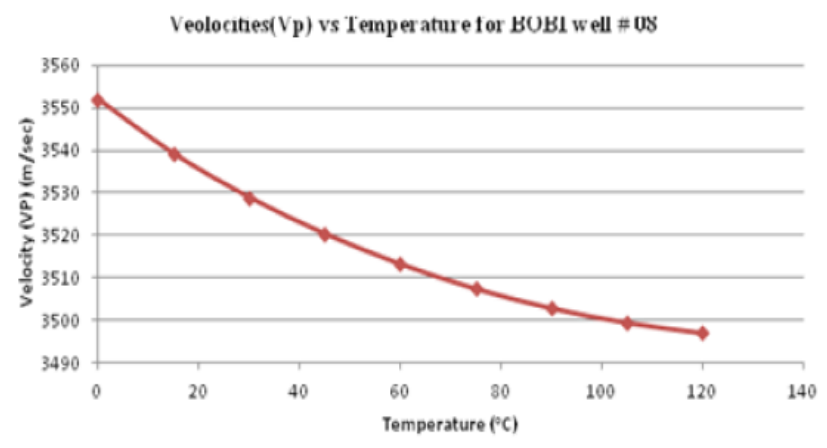

Figure 2: Graph between velocity $V_{\mathrm{P}}$ and Temperature of BOBI Well No: 08

This graph 2 shows the relationship between Velocity and Temperature, Which are inverse propotional to each other. Hence, as the velocity inceases Temperature decreases. Whereas, pressure has kept constant during performing the analysis.

Bulk modulus is having more sensitivity to water saturation. The bulk volume deformation results by the passage of seismic wave in pore volume change and pressure increases in the pore fluids increase in pressure hardens the rock frame and results in increase in bulk modulus due to the shear deformation there is no pore volume change produce and sometimes different fluids do not affect shear modulus, therefore any fluid saturation effect should correlate mainly to a change in bulk modulus ${ }^{16}$.

If we see the relation between density of gas and pressure it is concluded that with the increase in pressure the density also increases and it is shown in both wells $\mathrm{UCH}$ well and $\mathrm{BOBI}$ well. 


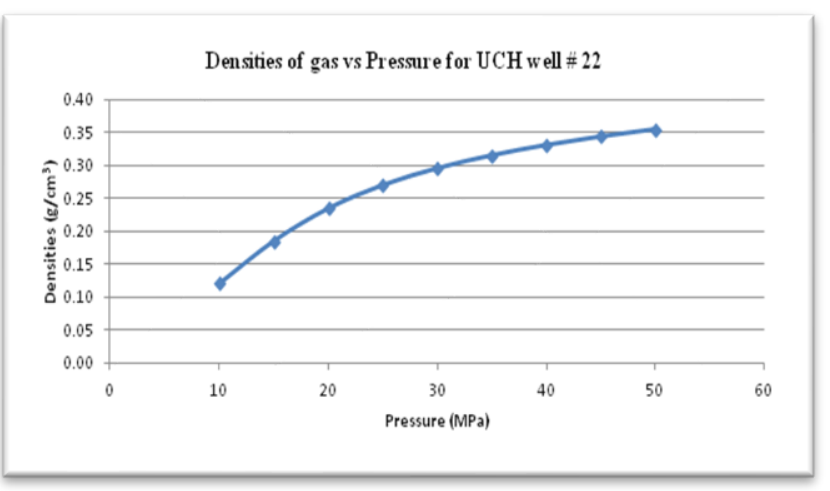

Figure 3: Graph between density of Gas and Pressure of UCH Well No: 22

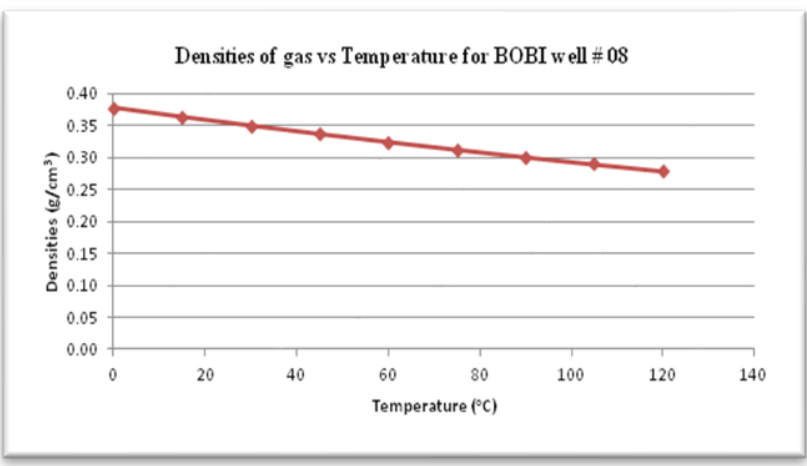

Figure 4: Graph between density of Gas and tepmerature of $\mathrm{BOBI}$ well No: 08

Above mentioned both graphs (3 and 4) show the relationship between Density and tepmerature, Which are inverse propotional to each other. Hence, as the density inceases tepmerature decreases. Whereaspressure has kept constant during performing the analysis.

Below mentioned both graphs show the relationship between Bulk modulus and Presseure, Which are directly propotional to each other. Hence, as the Bulk modulus inceases Presure also increases. Whereas, tepmerature has kept constant during performing the analysis.

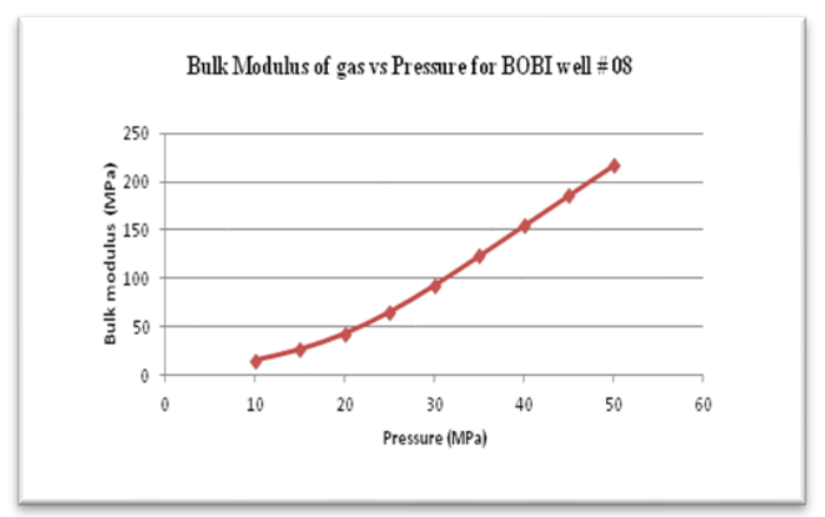

Figure 5: Graph between Bulk Modulus of Gas and Pressure of BOBI Well No: 08

Now we see the relationship between Bulk Modulus of gas and Temperature for the both well $\mathrm{UCH}$ well 22 and $\mathrm{BOBI}$ well 08 at constant pressure which is shown in Figure 6.

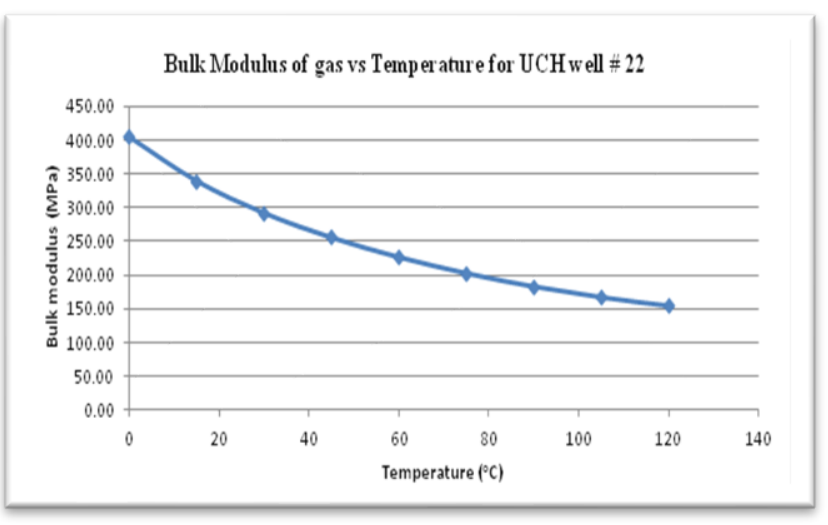

Figure 6: Graph between Bulk Modulus of Gas and Temperature of UCH Well No: 22

Above mentioned graph 6 show the relationship between Bulk modulus of gass and Temperature, Which are inverse propotional to each other. Hence, as the Bulk modulus inceases Temperature decreases. Whereas, Pressure has kept constant during performing the analysis.

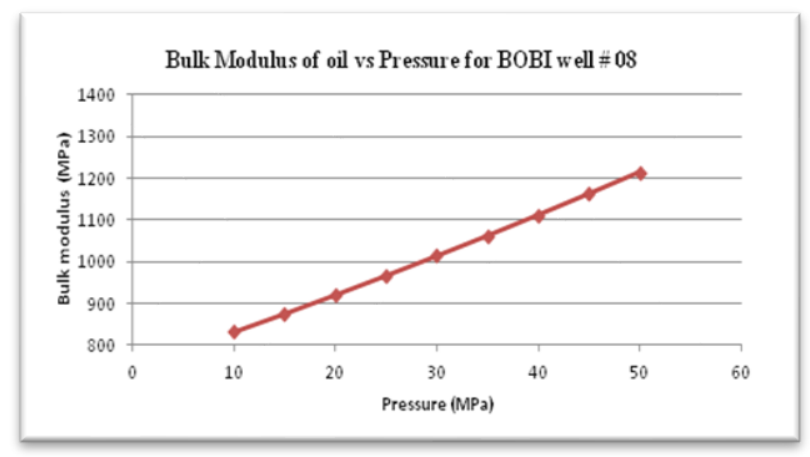

Figure 7: Graph between Bulk modulus of oil and pressure of $\mathrm{BOBI}$ well No: 08

Above mentioned graph 7 show the relationship between Bulk modulus of Oil and Presseure, Which are directly propotional to each other. Hence, as the Bulk modulus of Oil inceases Pressure also increases. Whereas, tepmerature has kept constant during performing the analysis.

Now we see the relationship between Bulk Modulus of oil and Temperature for the both wells $\mathrm{UCH}$ well 22 and $\mathrm{BOBI}$ well 08 at constant pressure the results are shown in Figure 8.

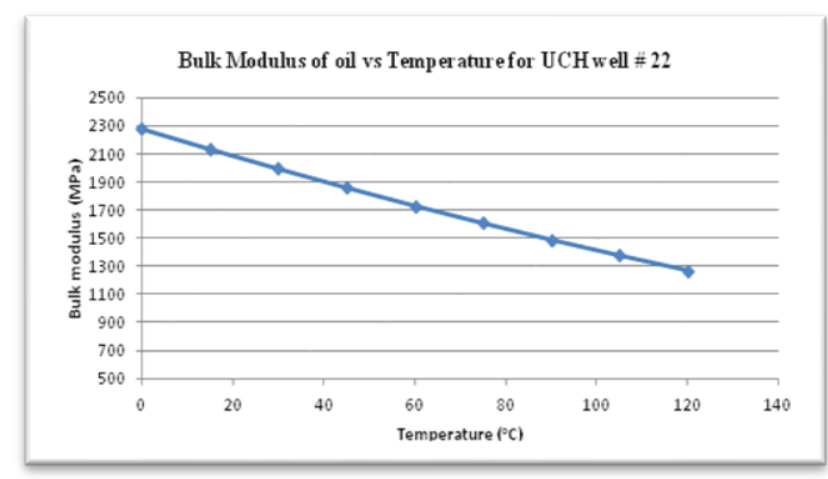

Figure 8: Graph between Bulk Modulus of Oil and Temperature of UCH Well No: 22 
Above mentioned graph 8 shows the relationship between Bulk modulus of Oil and Temperature, Which are inverse propotional to each other. Hence, as the Bulk modulus of Oil inceases Temperature decreases. Whereas, Pressure has kept constant during performing the analysis.

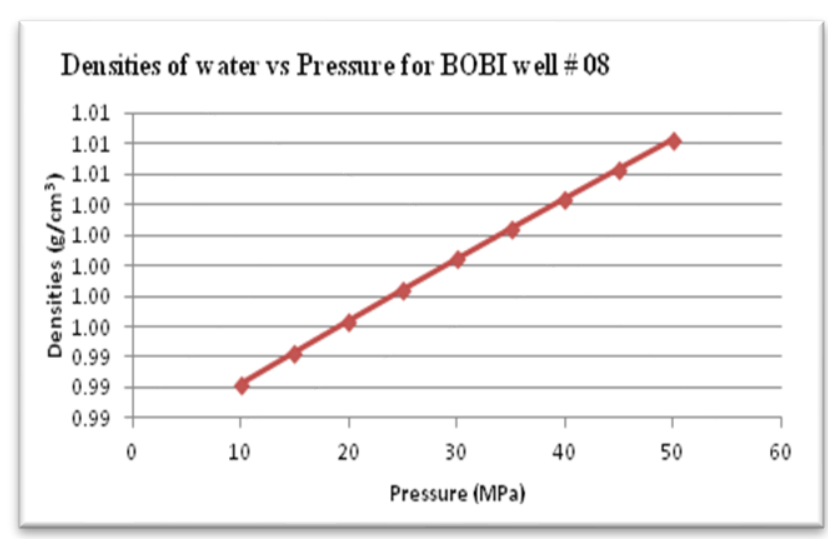

Figure 9: Graph between Densities of Water And pressure of $\mathrm{BOBI}$ well No: 08

Linear graph show the relationship between densities of water and Presseure, Which are directly propotional to each other. Hence, as the densities of water inceases Presure also increases. Whereas, Tepmerature has kept constant during performing the analysis.

Table 1: Table showing values of Coefficients for water properties computation

\begin{tabular}{|c|c|}
\hline \multicolumn{2}{|c|}{ Coefficients for water properties computation } \\
\hline$w(0,0)=1402.859$ & $w(0,2)=1.633786 * 10^{\wedge}(-7)$ \\
\hline$w(1,0)=5.023859$ & $w(1,2)=-1.08017 *^{*} 10^{\wedge}(-8)$ \\
\hline$w(2,0)=-5.690577 * 10^{\wedge}(-2)$ & $w(2,2)=2.215786 * 10^{\wedge}(-10)$ \\
\hline$w(3,0)=2.884942 * 10^{\wedge}(-4)$ & $w(3,2)=-2.420956^{*} 10^{\wedge}(-12)$ \\
\hline$w(4,0)=-8.238863 * 10^{\wedge}(-7)$ & $w(4,2)=9.711687^{*} 10^{\wedge}(-15)$ \\
\hline$w(0,1)=1.050469 * 10^{\wedge}(-2)$ & $w(0,3)=-3.889257^{*} 10^{\wedge}(-12)$ \\
\hline$w(1,1)=6.138077^{*} 10^{\wedge}(-5)$ & $w(1,3)=2.477679 * 10^{\wedge}(-13)$ \\
\hline$w(2,1)=-1.071154^{*} 10^{\wedge}(-6)$ & $w(2,3)=-5.088886 * 10^{\wedge}(-15)$ \\
\hline$w(3,1)=1.582394 * 10^{\wedge}(-8)$ & $w(3,3)=5.086237^{\wedge} 10^{\wedge}(-17)$ \\
\hline$w(4,1)=-6.839540^{\wedge} 10^{\wedge}(-11)$ & $w(4,3)=-1.845198 * 10^{\wedge}(-19)$ \\
\hline
\end{tabular}

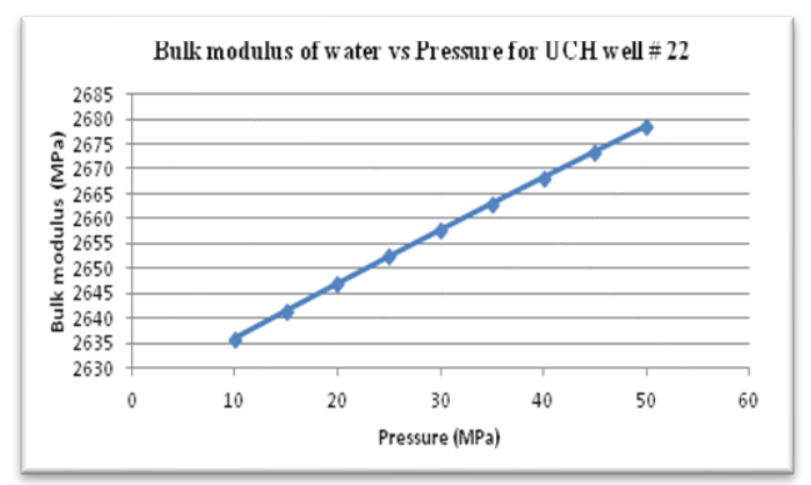

Figure 10: Graph between Bulk modulus of Water And pressure of UCH well No: 22
This straight line graph shows the relationship between Bulk modulus of water and Presseure, Which are directly propotional to each other. Hence, as the Bulk modulus of water inceases Presure also increases. Whereas, Tepmerature has kept constant during performing the analysis.

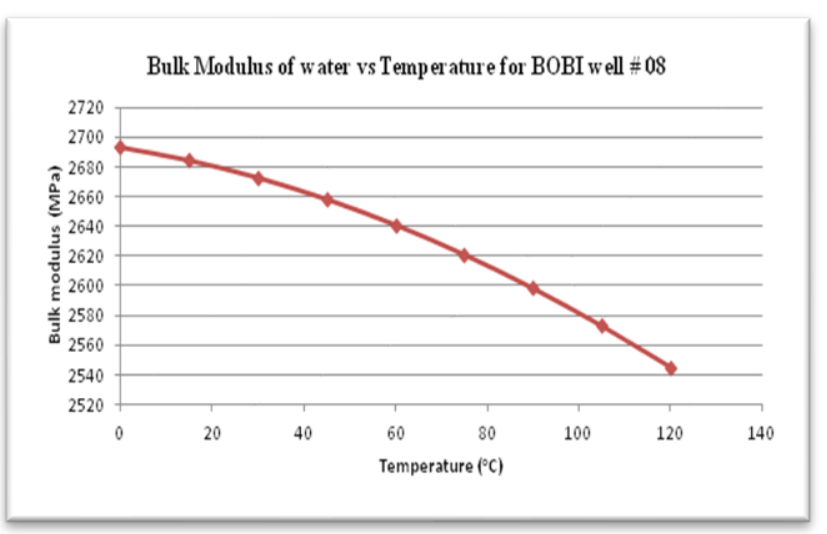

Figure 11: Graph between Bulk modulus of water and Tepmerature of BOBI well No:08

This straight line graph 11 shows the relationship between Bulk modulus of water and Tepmerature, Which are inverse propotional to each other. Hence, as the Bulk modulus of water inceases Tepmerature decreases. Whereas, pressure has kept constant during performing the analysis.

\section{CONCLUSION}

Our graphical result describes how seismic properties affected with reservoir fluids. Graphical results of two wells $\mathrm{UCH}$ well No: 22 and BOBI Well No: 08 shows that compressional velocities have direct relation with pressure. As pressure increases, velocities also increase if temperature is kept constant for oil, gas and water.

Similarly Bulk modulus, densities, effective density and bulk modulus of rock saturated within two wells for fluid oil, gas, and water also increases with pressure as temperature is kept constant.

On the other hand compressional velocities Bulk modulus, densities, effective density and bulk modulus of rock saturated within two wells for fluid oil, gas, and water have inverse relation with temperature. As temperature increases velocities Bulk modulus, densities, effective density and bulk modulus of rock saturated are decreases if pressure is kept constant. 


\section{REFERENCES}

1. Ahamad Muhammad Irfan, Song Jinxi, Sun Haotian, Wang Xinxin, Mehmood Muhammad Sajid, Sajid Muhammad, Su Ping, Khan Asif Jamal. Contamination Level, Ecological Risk and Source Identification of Heavy Metals in the Hyporheic Zone of the Weihe River, China. International Journal of Environmental Research and Public Health, 17, 2020, 1070; DOI: 10.3390 / ijerph17031070

2. Biot, M. A., Theory of propagation of elastic waves in a fluid-saturated porous solid. I. Low-frequency range: J. Acoust. Sot. Am., 28, 1956a, 168178.

3. Chen, C. T., Chen, L. S., and Millero, F. J., Speed of sound in $\mathrm{NaCl}, \mathrm{MgCl}, \mathrm{NazSO} 4$, and $\mathrm{MgSO} 4$ aqueous solutions as functions of concentration, temperature, and pressure: J. Acoust. Sot. Am., 63, 1978, 1795-180

4. Dodson, C. R., and Standing, M. B., Pressure-volume temperature and solubility relations for natural-gaswater mixtures: in Drilling and production practices, 1944, Am. Petr. Inst

5. Gassmann, F., Uber die Elastizitat poroser Medien: Vierteljahrsschrift der Natur for schenden Gesellschaft in Zurich Vol. 96, 1951, p. 1 - 23.

6. Johnson, R. C., Tables of critical flow functions and thermodynamic properties for methane and computational procedures for methane and natural gas: NASA SP-3074, National Aeronautics and Space Admin. 1972.

7. Thomas, L. K., Hankinson, R. W., and Phillips, K. A., Determination of acoustic velocities for natural gas: J. Petr. Tech., 22, 1970, 889-892.

8. Rao, K. S., and Rao, B. R., Study of temperature variation of ultrasonic velocities in some organic liquids by modified fixed path interferometer method: J. Acoust, Soc. Am., 31, 1959, 439-431.
9. Wang, Z., M.L. Batzle, and A.M. Nur, Effects of different pore fluids on seismic velocities in rocks. Canadian Journal of Exploration Geophysics, Vol.26, Nos. 1/2, 1990, p. $104-112$.

10. Wang, Z-W., 1988, Wave velocities in hydrocarbons and hydrocarbon saturated rocks-with applications to EOR monitoring: Ph.D. thesis, Stan

11. Rowe, A. M., and Chou, J. C. S., Pressure-volumetemperature- concentration relation of aqueous $\mathrm{NaCl}$ solutions: J. Chem. Eng. Data, 15, 1970, 61-66.

12. Potter, R. W., II, and Brown, D. L., 1977, The volumetric properties of sodium chloride solutions from 0 to 500 $C$ at pressures up to 2000 bars based on a regression of available data in the literature: U.S. Geol. Surv. Bull 1421-C.

13. Spiesberger, J. L., and Metzger, K., new estimates of sound speed in water: J. Acoust. Soc. Am., 89, 1991, 1697-1700.

14. Kestin, J., Khalifa, H. E., and Correia, R. J., Tables of the dynamic and kinematic viscosity of aueous $\mathrm{NaCl}$ solutions in the temperature range $20-150^{\circ} \mathrm{C}$ and the pressure range 0.1-35 MPa: J. Phys. Chem. Ref. Data, 10, 1981, 71-74.

15. Malthews, C. S., and Russel, D. G., 1967, Pressure buildup and flow tests in well, Monogram Vol. 1, H. L. Doherty Series: Soc. Petr. Eng. of AIME. McCain, W. D., 1973 Properties of petroleum fluids: Petroleum Pub. Co.

16. Muhammad Sajid, Muhammad Irfan Ahmed, Syed Salman Shafqat, Shahi Mulk, Mustafa Kamal Pasha. Study of Phosphorous oxide $\left(\mathrm{P}_{2} \mathrm{O}_{5}\right)$ and Iron oxide $\left(\mathrm{Fe}_{2} \mathrm{O}_{3}\right)$ in phosphorite of Hazara Basin, Pakistan. International Journal of Agrochemistry. 6(1), 2020, 46-51p.

Source of Support: None declared.

Conflict of Interest: None declared.

For any question relates to this article, please reach us at: editor@globalresearchonline.net

New manuscripts for publication can be submitted at: submit@globalresearchonline.net and submit_ijpsrr@rediffmail.com 